\title{
A scoping review of definitions and frameworks of intersectoral action
}

\author{
Revisão de âmbito das definições e modelos conceituais \\ de ações intersetoriais
}

Alejandra Dubois ${ }^{1}$

Louise St-Pierre ${ }^{2}$

Mirella Veras ${ }^{1}$
${ }^{1}$ Population Health Program, University of Ottawa. 25 University Private, Room 202B. 7043 Ottawa Ontario Canada. aduboi4@uottawa.ca ${ }^{2}$ Centre on Chronic Noncommunicable Disease Policy, World Health Organization.

\begin{abstract}
Intersectoral action is rooted in all health promotion activities because the determinants of health lie outside of the health sector. Despite the increasing use of these terms (intersectoral action, intersectoral action for health, intersectoral collaboration), often interchangeably, we noted a lack of consensus on their definitions and conceptualizations. The objective of this paper is to report the results of a scoping review of the use of definitions for a set of related terms as well as for conceptual frameworks, including the discussion of the evolution of those definitions and the sectors that use them. Finally, we propose a single definition for each term. We conducted a systematic search for documents published between January, 1960 and March, 2011 in English, French, Spanish and Portuguese. We retrieved 11 to 15 definitions per main term. Using a content analysis approach, an integrative conceptual definition was proposed for four main terms. Furthermore, in reviewing frameworks for potential use, we noted the lack of a comprehensive framework for intersectoral processes.
\end{abstract}

Key words Intersectoral action, Intersectoral action for health, Intersectoral collaboration, Social determinants of health
Resumo Ação intersetorial faz parte de todas as atividades de promoção da saúde, porque a maioria dos seus determinantes estão localizados fora desse setor. Apesar do crescente uso desses termos (ação intersetorial, ação intersetorial para a saúde e colaboração intersetorial), muitas vezes utilizados como sinônimos, notamos uma falta de consenso em suas definições e conceituações. O objetivo deste trabalho é descrever o resultado de uma revisão em busca de definições para um conjunto de termos relacionados, bem como para modelos conceituais, incluindo uma discussão da evolução dessas definições e os setores que os utilizam. Finalmente, nós propomos uma definição única para cada termo. Assim, realizamos uma busca sistemática de documentos publicadas entre janeiro de 1960 e março de 2011, em inglês, francês, espanhol e português. Foram encontrados entre 11 e 15 definições por termo principal. Neste contexto, propomos uma definição conceitual integrativa para quatro termos principais, usando uma abordagem de análise de conteúdo. Além disso, na revisão de modelos conceituais, percebemos a falta de um abrangente de processos intersetoriais.

Palavras-chave Ação intersetorial, Ação intersetorial para a saúde, Colaboração intersetorial, Determinantes sociais da saúde 


\section{Introduction}

Since the Alma-Ata Declaration of 1978 and the rise of the concept of Health for All, momentum has grown internationally for public health policies to work upstream and outside the health sector $^{1,2}$. Indeed, as most of the socio-economic conditions in which people are born, live and work, commonly referred as the social determinants of health, are outside the health sector realm, intersectoral collaboration emerges as the strategy of choice to act on those determinants ${ }^{3}$. The Ottawa Charter of 1986, a universally recognized milestone in the story of public health, highlighted five main strategies for effective health promotion: building healthy public policy, strengthening community action, developing personal skills, creating supportive environments, and re-orienting health services ${ }^{4}$. In a 2006 review assessing the effectiveness of the first four strategies, Jackson et al. concluded that No strategy stands on its own as a clear success - they all need to act in conjunction with each other and certain supporting actions in order to be effective $e^{5}$. The authors also highlighted intersectoral collaboration and interorganizational partnerships as a cross-cutting action that needs to occur at the structural, social and personal levels and that needs to be implemented in conjunction with all of the major health promotion strategies of the Ottawa Charter ${ }^{5}$.

But what does intersectoral collaboration mean, and how can these intersectoral processes be achieved? Despite the vast and growing literature referring to intersectoral processes, a lack of consensus still exists regarding definition of terms. In fact, similar terms such as intersectoral action, intersectoral action for health and intersectoral collaboration appear to be used interchangeably. However, does collaboration entail action? And do all intersectoral processes gravitate around health? Marcus Tullius Cicero (106-43 B.C), a Roman orator and politician, argued that any rational discussion of a subject should begin with a definition to clarify the subject of discussion. Indeed, building on the work of concept analysts such as Rodgers ${ }^{6}$, Hupcey and Penrod $^{7}$, we believe that concepts are the backbone of theory in practice as sharing a common understanding of concepts helps scholars and practitioners 'to organize meaning to understand complex human experiences and behaviours in ways that influence the practice' ${ }^{7}$. It is our intention to contribute to the clarification of the concept of intersectoriality, under its diverse forms and their current use, and uncover the attributes of the concept as a basis for further development of theory and practice.

As the first phase of a qualitative research project, we have undertaken a literature review which had a twofold aim: to untangle the different concepts used in the literature to define intersectoral processes (intersectoral action, intersectoral action for health, intersectoral collaboration, and intersectoral policy) and to identify potential conceptual frameworks that could be applied at a subsequent research phase. Conceptual frameworks were narrowly defined as a visual model such as a diagram, an item list, a graph or a figure that identifies and organizes the main ideas underlying the term under analysis. The objectives of this paper are: a) review the existing literature in search of definitions of a set of related terms as well as of conceptual frameworks; b) discuss the evolution of those definitions of terms and the sectors that use them; and c) propose a single definition for each term.

\section{Methods}

This scoping review was informed by the Arksey and O'Malley framework ${ }^{8}$, which has five stages: 1) Identifying the research question; stage 2) Identifying relevant studies; stage 3) Study selection; stage 4) Charting the data and stage 5) Collating, summarizing and reporting the results of the scoping review. This review was undertaken for the following terms: a) Intersectoral action, b) Intersectoral action for health, c) Intersectoral collaboration, and d) Intersectoral policy. The objective of this exercise was to flag definitions and conceptual frameworks previously published, with the ultimate goal of developing, at a further stage, a comprehensive conceptual framework of intersectoral processes that leads to improved population health. It is important to note that the intent was not to conduct an exhaustive systematic literature review, but to undertake a critical review of previously published definitions to identify key documents in the field. A particular emphasis was given to documents elaborated by groups of experts or recognized organizations. The search was expected to go beyond the health sector literature in order to capture the discussions on these terms in relevant areas such as public administration, policy making, social work and education. This project was conducted as a component of a larger literature review commissioned by the World Health Organization Collaborating Centre on 
Chronic Non communicable Disease Policy, hosted by the Public Health Agency of Canada. For this phase, a search strategy was designed by the two first authors and conducted by two of the authors during the month of March 2011 (MV, $\mathrm{AD})$. The larger literature review project targeted ten different terms: intersectoral action for health, intersectoral action, intersectoral collaboration, intersectoral policy, horizontal linkages, health in all policies, health for all, health impact assessment, joined up government, and whole of government approach. The focus of this paper is on the first four of those terms.

\section{Identification of relevant studies according to the research question and study selection}

\section{Databases included}

The search was conducted with the assistance of an experienced academic librarian. The following six databases, available through the University of Ottawa library, were included: Web of Science (Social Sciences Citation Index), Scholars Portal, Scopus, HealthStar, Longwoods Publishing, and Canadian Public Policy Collection. The GreyNet database and Google Scholar were originally listed but finally excluded from the search. GreyNet was excluded after an unsuccessful search using a few terms of the review in several of its databases related to health and social sciences. Google Scholar was excluded because of the extensive and unrefined amount of results obtained for each term.

\section{Inclusion Criteria}

The documents included in the search strategy had to meet the following criteria: a) the four English terms identified above are included as key words or in the English abstract of the document; b) selected documents are written in any of the following four languages: English, French, Spanish and Portuguese, but they include at least one of the selected English terms either in the English abstract or among the key words; c) documents were published between January, 1960 and March, 2011; and d) a significant definition of the terms is presented in the body of the document in any of the four indicated languages.

\section{Charting the data and collating the results}

\section{Data Extraction}

Screening Phase I: All the references meeting the first three inclusion criteria were entered into RefWorks (Online bibliographic manage- ment program). Using an ad hoc template, the key features of each study were extracted. Those key features were: author name(s), publication year, inclusion of a definition ('yes' ; 'no'; 'maybe'), inclusion of a potential framework for the flagged term ('yes' or 'no'), sector (health, agriculture, environment, etc.), country where study was conducted, when applicable, language of the document, institutional affiliation of authors, and source and name of the book when the document was a book.

Screening Phase II: In searching for a definition of key terms in the body of the documents, two different screening processes were used based on the document format. When a PDF digital version of the document was accessible, each relevant key term was flagged using the 'search' tool in Adobe Reader. Each appearance of the term in the body of the document was read within its context in order to flag a potential definition. If a PDF digital version was not available, the entire document was reviewed in order to track a potential definition. A table of translated key terms was created to allow for flagging the definitions in the body of documents written in French, Spanish or Portuguese (see table I). All screened references were classified as 'yes,' 'no' or 'maybe.' Documents with an unclear definition were considered 'maybe' and were discussed between authors to reach a consensus for inclusion or exclusion. To flag potential conceptual frameworks, all the references retained at Screening Phase I were reviewed in search of potentially relevant diagrams or models.

Sorting and Scoping Phase: The articles were sorted by terms and by the sector of affiliation of the authors (health, public administration, policy making, etc.). The identified papers were downloaded when possible and organized in electronic folders.

Reviewing Phase: All the references flagged during this exercises were reviewed in detail by the first author to verify that they complied with the inclusion criteria. Additional references resulted from hand-searching the reference lists of the reviewed documents.

\section{Results}

Chart 1 presents the number of references retained at the final stage of this review process. The complete list of substantive definitions retained at the end of the exercise can be requested by contacting the corresponding author. 
Chart 1. Main Terms in English, French, Portuguese and Spanish and Number of References Retained at the End of the Process.

\begin{tabular}{|c|c|c|c|}
\hline & $\begin{array}{l}\text { Intersectoral } \\
\text { action }\end{array}$ & $\begin{array}{l}\text { Intersectoral action } \\
\text { for health }\end{array}$ & $\begin{array}{l}\text { Intersectoral } \\
\text { collaboration }\end{array}$ \\
\hline Main Term in French & $\begin{array}{c}\text { Action } \\
\text { intersectorielle }\end{array}$ & $\begin{array}{c}\text { Action intersectorielle } \\
\text { pour la santé }\end{array}$ & $\begin{array}{l}\text { Collaboration } \\
\text { intersectorielle }\end{array}$ \\
\hline Main Term in Portuguese & Ações intersetoriais & $\begin{array}{c}\text { Ação intersetorial para } \\
\text { a saúde }\end{array}$ & $\begin{array}{l}\text { Colaboração } \\
\text { intersectorial }\end{array}$ \\
\hline Main Term in Spanish & $\begin{array}{c}\text { Acción } \\
\text { intersectorial }\end{array}$ & $\begin{array}{l}\text { Acción intersectorial } \\
\text { para la salud }\end{array}$ & $\begin{array}{l}\text { Colaboración } \\
\text { intersectorial }\end{array}$ \\
\hline $\begin{array}{l}\text { Number of references retained at the end } \\
\text { of the process }\end{array}$ & 15 & 14 & 11 \\
\hline
\end{tabular}

\section{Intersectoral Action}

At the end of the review, 15 different references containing a definition of the term 'intersectoral action' were identified. We observed no uniformity on the wording of definitions emerging from the literature. Many of them refer to the definition of intersectoral action for health, and many authors explicitly indicate that terms are being used interchangeably (intersectoral action, intersectoral collaboration, intersectoral action for health). Most of the definitions were published from the year 1994 onward. The only sector that seems to have published definitions of the term is the health and social services sector. Canada and WHO are very present in the field. Only few other countries (Netherlands, UK, Brazil and Australia) have authors who contributed to the development of a definition. Only one publication in Spanish (although written by $\mathrm{Ca}$ nadian researchers) and one in Portuguese were identified. Several French-Canadian authors have largely contributed to the development of the field ${ }^{9-12}$. The vast majority of documents are available only in English. Documents prepared by Canadian Federal institutions (Health Canada, PHAC, Senate) are published in both official languages.

Eight definitions were highlighted for further discussion:

'Working with more than one sector of society to take action on an area of shared interest. Sectors may include government departments such as health, education, environment and justice; ordinary citizens; non-profit societies or organizations; and business' ${ }^{\text {'13,14 }}$

'Linking diverse stakeholders from a range of sectors including public and private agencies and organizations'15

'Concerted programming and joint development of health, social and educational policies' ${ }^{\text {'6 }}$

Intersectoral action 'in which the health sector and other relevant sectors of the economy collaborate, or interact to pursue health goals' (citing World Health Organization Europe 2004) ${ }^{17}$

'Coordination among and collaboration with a variety of stakeholders' ${ }^{18}$

'Collaboration between different sectors of the community' ${ }^{19}$

'Unir esfuerzos para conseguir mejores resultados que los que se obtendrían trabajando de forma aislada'20 (To join efforts to achieve better results than those obtained working in isolation Free translation )

'A ação intersetorial não é um processo espontâneo, e sim organizado e coletivo; tem a ver com a criação de espaços comunicativos, com a capacidade de negociar e gerenciar conflitos' (Vieira, 2010, quoting Campos, 2000) 21,22 (Intersectoral action is not a spontaneous process, but organized and collective; it has to do with the creation of communicative spaces, with the ability to negotiate and manage conflicts - Free translation)

The analyses of their wording led us to several observations. First, five of these definitions are inclusive and explicit in terms of the sectors that 
need to be involved, including both public and private domains. Indeed, only one among the eight definitions circumscribes to the public policy realm ${ }^{16}$. Second, most of the definitions refer to intersectoral action as a process ${ }^{22}$, a practice ${ }^{23}$ a collaboration ${ }^{18,19,24}$, a coordination ${ }^{18}$, or an interaction $^{24}$. Third, it is interesting to highlight that only one of these definitions emphasises the importance of the conditions and management skills required to achieve intersectoral action ${ }^{22}$. Finally, several of these definitions explicitly identify the goal or purpose of intersectoral action (i.e.: to take action on an area of shared interest $^{13}$ to pursue health goals ${ }^{24}$; to achieve better results than those obtained working in isolation ${ }^{20}$.

\section{Intersectoral Action for Health}

At the end of our literature review, 14 different references containing a definition of the term 'intersectoral action for health' were identified. The definition from Elizabeth Harris et al. from the National Centre for Health Promotion of the University of Sidney and the Commonwealth Department of Human Services and Health ${ }^{25}$, appears to be the foundational one for the concept of intersectoral action for health. It has been reproduced by all the other sources, at times with minor wording adjustments. It reads as follows:

A recognised relationship between part or parts of the health sector and part or parts of another sector, that has been formed to take action on an issue or to achieve health outcomes, (or intermediate health outcomes) in a way which is more effective, efficient or sustainable than could be achieved by the health sector working alone.

Authors refer to it as the Harris definition or the National Centre for Health Promotion definition. Two years after the publication of Harris' team work, an international Conference on Intersectoral Action for Health, organized by WHO, was held in Halifax, Canada. Among 63 international participants, Harris attended the event. Definitions from diverse conference working documents were reviewed by participants, but the final definition emerging from that event was a slightly modified version of the original Harris definition. Since then, the conference definition has been profusely cited by subsequent authors and even reproduced in the WHO Health Promotion Glossary ${ }^{26}$. It is being referred as the WHO definition, although search engines identify Wilfreid Kreisel as the main author of the conference report. In fact, Kreisel signed the preface in his capacity of Executive Director of the division of Health and Environment of WHO at the time of the conference ${ }^{27}$. Most authors cite Kreisel in their list of references. Its definition of Intersectoral Action for Health (IAH) reads as follows:

A definition of IAH

There was little formal discussion of the definition of IAH although several of the conference working documents provided definitions. The following definition appeared to reflect the consensus of participants:

a recognized relationship between part or parts of the health sector with part or parts of another sector which has been formed to take action on an issue to achieve health outcomes or intermediate health outcomes in a way that is more effective, efficient or sustainable than could be achieved by the health sector acting alone. National Centre for Health Promotion.

Among the 14 definitions retrieved, nine presented either the Harris et al..$^{25}$ or the Kreisel $^{27}$ definition in their integrality. The Public Health Agency of Canada (PHAC, 2008) introduced an important variation to this classic definition. Indeed, in the context of an analysis of 18 international case studies, the working team understands intersectoral action for health to refer to actions undertaken by sectors outside the health sector, possibly, but not necessarily, in collaboration with the health sector, on health or health equity outcomes or on the determinants of health or health equity'. In this sense, these authors are the first to conceive the health sector as being involved in the relationship on an optional, but not mandatory basis. Furthermore, they also state 'Intersectoral action for health for this study is defined as: a recognized relationship between part or parts of different sectors to take action on issues to improve health and health equity?.

In terms of general observations regarding origin and history, we noted that all the definitions retrieved were published from the year 1995 onward. However, the seminal report of Harris et al., although published in 1995, was already building on an extensive bibliography related to intersectoriality, which was included in the report's reference list. This observation confirms that research on this area had been done for several decades even prior to tackling the effort to define the terms. Indeed, since the 1970s, scholars in the field of interorganizational relations have been the precursors to the study of intersectoral collaboration in the health promotion arena ${ }^{9,28}$.

The only sector that has been publishing definitions of this term is the health and social 
services sector. Canada, Australia and to a certain extent Finland are present in the field. Authors from no other countries were identified. Only one definition in Spanish from Canadian authors was retrieved (which is a translation of the WHO definition); the vast majority have been published in English, and when Health Canada or PHAC is the author, in French as well.

\section{Intersectoral Collaboration}

At the end of our literature review, 11 different references containing a definition of the term 'intersectoral collaboration' were identified. Eight of them were rooted on the Kreisel definition of intersectoral action for health.

Definitions of the term 'intersectoral collaboration' are available in the literature since 1993, although the majority of texts retrieved were published from 1998 onwards. Besides international organizations, such as WHO and the Alliance for healthy cities $^{29}$, authors from the Netherlands, Sweden, Australia, Nigeria and Canada have included definitions of this term. All the documents identified were written in English.

The terms 'intersectoral collaboration' and 'intersectoral action for health' seem to be used interchangeably in the literature. Two reasons might explain this fact:

A) the term 'intersectoral collaboration' appears to be used almost exclusively by the health sector;

B) most of the definitions retrieved stem from the same root: The 1995 Harris et al. definition.

It is interesting to highlight that the earliest definition retrieved (1993) is the only one not pertaining to the health sector. Indeed, it pertains to the agriculture realm and its author is from the Netherlands. It reads as follows: 'Intersectoral collaboration is considered to be an action between sectors through a series of negotiations where personal, face-to-face contacts play an important role'30.

The 1998 WHO Health Promotion Glossary proposes the Harris et al. definition as well. However, it also points that: intersectoral collaboration is understood as cooperation between different sectors of society such as the public sector, civil society and the private sector. This appears to be a more inclusive definition, instead of targeting health as a central ingredient of the equation.

\section{Intersectoral Policy}

Only one definition for this term was retrieved: 'Inter-sectoral Policy: Health-orientated policy affecting sectors outside health services but usually evolved in collaboration with the health sector' ${ }^{31}$. As well, some elements of a definition were found for a related term: Intersectoral action in health policy, which implies the cooperation of politicians outside the health sector, so there will inevitably be a trade-off of sectoral interests' ${ }^{32}$.

\section{Conceptual Frameworks}

No comprehensive conceptual framework emerged from the literature reviewed. However, among the 35 single references flagged (occasionally more than one definition per reference was retrieved) eight of them offer several elements deserving integration in an overarching model. Listing them in chronological order, we observed that the first two models focus on the conditions required for succeeding. Indeed, Harris et al. list six conditions for effective intersectoral action: necessity, opportunity, capacity, relationships, planned action and sustained outcomes ${ }^{25}$. Kreisel reiterates the same conditions and introduces visual diagrams developed by workshop participants $^{27}$. Health Canada describes stages and challenges of the intersectoral action journey ${ }^{13}$, while Ramsden et al. ${ }^{33}$ differentiate among the different levels of partnerships (communication, coordination, co-operation and collaboration). The latter authors propose as well a grid to categorize examples of low versus high levels of commitment, formality, personal contact and autonomy. Frankish et al. define levels of internal action and intersectoral collaboration ${ }^{34}$, and PHAC (2008) identifies key mechanisms and tools to support intersectoral action for health and health equity based on analysis of 18 international case stud$\mathrm{ies}^{35}$. Geneau ${ }^{1}$ discusses the importance of coordination, governance and accountability mechanisms, and, finally, Wagemakers et al. ${ }^{36}$ introduce the most encompassing model, by identifying levels of action (individual, organizational, coalition and community) and categories of variables to consider (context, participants/stakeholders, partnerships/coalitions, process and outcomes). 
To our knowledge, this is the first review aiming to disentangle concepts related to intersectoriality and to understand their evolution. Furthermore, we aimed to identify a single definition per term. However, when a consensual definition of the term was not found in the literature, we crafted our own definitions building on concept analysis approach ${ }^{7}$ and using the following basic structure:

- WHAT: What is the action? For instance: a process, an approach, a collaboration, a coordination, etc.

- WHO: Who are the actors conducting the action?

- WHY: What are the goals or objectives of the action?

From our perspective, these are the three basic elements that should be in a definition. It is possible however to identify a fourth element in definitions provided by different authors. That fourth element represents the CONDITIONS under which the action is conducted. However, it was agreed that unless all the conditions are listed, this element should be dismissed because including a few but not all would prioritize only those identified.

Therefore, for the first term that lacked a consensus, we believe that the following is the best definition:

Intersectoral Action:

Working with more than one sector of society to take action on an area of shared interest to achieve better results than those obtained working in isolation. Sectors may include government departments such as health, education, environment, justice, etc.; ordinary citizens; non-profit societies or organizations; and business.

WHAT: Working with (others) to take action on an area of shared interest

WHO: more than one sector of society (the health sector does not need to be an actor)

WHY: to achieve better results than those obtained working in isolation (health outcomes do not need to be part of the expected results)

Regarding the second term, with the exception of the perspective of PHAC $^{35}$ discussed earlier, there seems to be a consensus in the use of the WHO definition, and our recommendation is to adopt it as such:

Intersectoral Action for Health or IAH:

A recognized relationship between a part or parts of the health sector with a part or parts of another sector that has been formed to take ac- tion on an issue to achieve health outcomes or intermediate health outcomes in a way that is more effective, efficient or sustainable than could be achieved by the health sector acting alone.

WHAT: a recognized relationship (between sectors) to take action on an issue

WHO: part or parts of the health sector with part or parts of another sector

WHY: to achieve health outcomes or intermediate health outcomes in a way that is more effective, efficient or sustainable than could be achieved by the health sector acting alone.

Our recommendation is to apply the same definition for the terms intersectoral collaboration and intersectoral action where the health outcomes are not emphasized and where the health sector is not necessarily an actor. On the other hand, the terms intersectoral collaboration for health should carry the same definition as intersectoral action for health.

Intersectoral Action or Intersectoral Collaboration:

Working with more than one sector of society to take action on an area of shared interest to achieve better results than those obtained working in isolation. Sectors may include government departments such as health, education, environment, justice, etc.; ordinary citizens; non-profit societies or organizations; and business.

Intersectoral Action for Health or IAH or Intersectoral Collaboration for Health:

A recognized relationship between a part or parts of the health sector with a part or parts of another sector that has been formed to take action on an issue to achieve health outcomes or intermediate health outcomes in a more effective, efficient or sustainable way than could be achieved by the health sector acting alone.

\section{Limitations}

We acknowledge a few limitations in our literature review. First, during the screening phase, if terms related to the intersectoral approach were not worded exactly as in our original list of main terms, those references were missed. It would have been useful to include terms such as intersectoriality,' 'intersectoral cooperation, and even the split term 'inter-sectoral'. Second, as this exercise constitutes only a portion of a larger review that included ten different terms, we were not able to determine the number of references retrieved at each stage for our subset of terms. Third, the databases chosen for this search probably introduced a publication bias by privileging Canadian 
content. Finally, as we conducted this review in March 2011, documents published after that date, such as the seminal works on intersectoral action for health equity completed by Shankardass et al. ${ }^{37}$ and Ndumbe-Eyoh and Moffatt ${ }^{38}$ would need to be included in a future update. Additionally, there are several articles recently published in the topic in a special edition of a Brazilian Journal that had focus on intersectoriality ${ }^{39-42}$.

\section{Conclusion}

Getting to an agreement on terms and their meaning is an important step not only in all research endeavors, but in particular in action oriented, collaborative activities such as intersectoral population health interventions and health promotion in general. This project allowed us to disentangle related concepts, to understand their evolution, and to come up with a recommendation of definitions to be used for three commonly used terms: 'intersectoral action', 'intersectoral action for health', and 'intersectoral collaboration'. Furthermore, in reviewing frameworks for potential use, we noted the lack of a comprehensive, explanatory conceptual model for intersectoral process. On this basis, we will pursue our research in order to build a theoretical framework to be empirically tested using qualitative approaches that will allow us to assess as well the importance and practicality of intersectoral action. Both theoretical and applied research is required to help us build stronger case studies to further our understanding of relationships between sectors pursuing a common goal.

\section{Collaborations}

A Dubois, L St-Pierre and M Veras worked on the conception and delimitation. M Veras and A Dubois worked on the acquisition of the data and in technical procedures. A Dubois, M Veras and L St-Pierre worked in data interpretation. A Dubois, M Veras and L St-Pierre worked in the preparation and writing the manuscript. A Dubois, L St-Pierre and $M$ Veras worked on final approval.

\section{Acknowledgements}

Authors are indebted to Dr. Sylvie Desjardins (WHO Collaborating Centre on Chronic Non communicable Disease Policy) for her mentorship. Technical assistance provided by the University of Ottawa team of librarians (Cynthia Bail, Tea Rokolj, Lee-Anne Ufholz, and Patrick Labelle) is greatly appreciated by the authors.

This work was supported by the WHO Collaborating Centre on Chronic Non communicable Disease Policy and the Public Health Agency of Canada. During the course of this work, Alejandra Dubois held doctoral scholarships from the Canadian Institutes of Health Research (CIHR), the NETwork in Population Health Intervention Research (PHIRNET) and the Research Chair in Governance and the transformation of organizations and health systems, in collaboration with the Working Group on Public Policy and Health (GÉPPSS). 


\section{References}

1. Robert G. Public Health Agency of Canada,WHO Collaborating Centre on Chronic Non Communicable Disease Policy. Mobilizing intersectoral action to promote health [electronic resource]: The case of ActNowBC in british columbia, Canada. 2009. [acessado 2015 agosto 17]. Disponível em: http://www.phac-aspc.gc. ca/publicat/2009/ActNowBC/index-eng.php\#toc

2. World Health Organization (WHO). Closing the gap in a generation: Health equity through action on the social determinants of health: Final report of the commission on social determinants of health. Geneva: WHO; 2008.

3. World Health Organization (WHO). Intersectoral action to tackle the social determinants of health and the role of evaluation. Geneva: WHO; 2010. [acessado 2015 agosto 17]. Disponível em: http://webcache.googleusercontent.com/search?q=cache:1RRDWrLoVicJ:whqlibdoc.who.int/hq/2010/WHO_ETH_10.1_eng. pdf+Intersectoral+action+to+tackle+the+social+determinants + of + health + and + the + role + of + evaluation $\& \mathrm{~cd}=1 \& \mathrm{hl}=\mathrm{en} \& \mathrm{ct}=\mathrm{clnk} \& \mathrm{gl}=\mathrm{ca} \& \mathrm{client}=$ firefox-a\&source $=w w w . g o o g l e . c a$

4. World Health Organization (WHO). The ottawa charter of health promotion. Geneva: WHO; 1986.

5. Jackson SF, Perkins F, Khandor E, Cordwell L, Hamann S, Buasai S. Integrated health promotion strategies: A contribution to tackling current and future health challenges. Health Promot Internation 2006; 21(Supl. 1):75-83.

6. Rodgers BL. Concept analysis: An evolutionary view. In: Rodgers BL, Knafl KA, editors. Concept development in nursing: Foundations, techniques, and applications. $2^{\text {nd }}$ ed. Philadelphia: W. B. Saunders; 2000. p. 77-102.

7. Hupcey JE, Penrod J. Concept analysis: Examining the state of the science. Research and Theory for Nursing Practice 2005; 19(2):197-208.

8. Arksey H, O'malley L. Scoping studies: Towards a methodological framework. International Journal of Social Research Methodology 2005; 8(1):19-32.

9. Fortin JP, Groleau G, Lemieux V, O’Neill M, Lamarche P. Intersectoral action for health. summary of research findings. Antigonish: National Collaborating Centre for Determinants of Health; 1994.

10. Ouellet F, Paiement M, Tremblay PH. L'action intersectorielle, un jeu d'équipe. 1995.

11. Lebeau A, Vermette G, Viens C. Développer la concertation intersectorielle : Des conditions à l'action. Ruptures, revue transdisciplinaire en santé. 1998; 5(2):194.

12. Pour sortir des sentiers battus: L'action intersectorielle en santé mentale. Sainte-Foy: Publications du Québec; 2002.

13. Health Canada. Intersectoral action toolkit: The cloverleaf model for success. Ottawa: Health Canada; 2000.

14. Perera MALR. Intersectoral action for health in sri lanka. A case study commissioned by the health systems knowledge network. Colombo: Intersectoral action for health in Sri Lanka; 2006.

15. Rissel C, Rowling L. Intersectoral collaboration for the development of a national framework for health promoting schools in australia. J Sch Health 2000; 70(6):248-250.
16. El Ansari W. Collaborative research partnerships with disadvantaged communities: Challenges and potential solutions. Public Health 2005; 119(9):758-770.

17. Stewart MJ, Neufeld A, Harrison MJ, Spitzer D, Hughes $\mathrm{K}$, Makwarimba E. Immigrant women family caregivers in Canada: Implications for policies and programmes in health and social sectors. Health Soc Care Community 2006; 14(4):329-340.

18. Keon W. Fourth report of the subcommittee on population health of the standing senate committee on social affairs, science and technology. Ottawa: Parliament of Canada; 2008.

19. Lal S, Mercier C. Intersectoral action to employ individuals with mental illness: Lessons learned from a local development initiative. Work 2009; 33(4):427-437.

20. Zunzunegui MV, Béland F. Intersectoral policies to meet the challenge of active aging. SESPAS report 2010. Gaceta Sanitaria 2010; 24(Supl. 1):68-73.

21. Vieira JMR, Garnelo L, Hortale VA. Analysis of primary care in five municipalities of western amazonia, with emphasis on family health program. Saude Soc 2010; 19(4):852-865.

22. Campos GWS, editor. Um método para análise e cogestão de coletivos. São Paulo: Hucitec; 2000.

23. Wimmer GF, De Oliveira Figueiredo G. Collective action for quality of life: Autonomy, transdisciplinarity and intersetoriality. Cien Saude Colet 2006; 11(1):145154.

24. Stewart MJ, Neufeld A, Harrison MJ, Spitzer D, Hughes K, Makwarimba E. Immigrant women family caregivers in Canada: Implications for policies and programmes in health and social sectors. Health and Social Care in the Community 2006; 14(4):329-340.

25. Harris E, Wise M, Hawe P, Finlay P, Nutbeam D. Working together: Intersectoral action for health. [Working together: intersectoral action for health.]. Canberra: Australian Government Publishing Service; 1995.

26. World Health Organization. Health promotion glossary. Geneve: WHO; 1998. (HPR/HEP/98.1).

27. Kreisel W. Intersectoral action for health: A cornerstone for health for all in the 21 st century. World Health Stat Q 1998; 51(1):75-78.

28. Delaney FG. Muddling through the middle ground: Theoretical concerns in intersectoral collaboration and health promotion. Health Promot Internation. 1994; 9(3):217-225.

29. Alliance for healthy cities. Updated UNK. [cited 2013 Dic 12]. Available from: http://www.alliance-healthycities.com/htmls/glossary/index_glossary.html.

30. Vaandrager HW, Koelen MA, Ashton JR, Revuelta CC. A four-step health promotion approach for changing dietary patterns in europe. The European Journal of Public Health 1993; 3(3):193-198.

31. Nutbeam D. Health promotion glossary. Health Promotion. 1986; 1(1):113-127.

32. Mooy JM, Gunning-Schepers LJ. Computer-assisted health impact assessment for intersectoral health policy. Health Policy. 2001; 57(3):169-177. 
33. Ramsden VR, Osborne C, Turner S, White H. Building community capacity. In: Guiding facilitation in the canadian context : Enhancing primary health care. Electronic document ed. St. John's, NL, Canada: Department of Health and Community Services, Government of Newfoundland and Labrador; 2006:46. [acessado 2015 agosto 17]. Disponível em: http://toolkit.cfpc.ca/ en/interdisciplinary-collaboration/documents/Chapter6.pdf.

34. Frankish CJ, Moulton GE, Quantz D, Carson AJ, Casebeer AL, Eyles JD, Labonte R, Evoy BE. Addressing the non-medical determinants of health - A survey of Canada's health regions. Can J Public Health 2007; 98(1):41-47.

35. Public Health Agency of Canada, World Health Organization. Health equity through intersectoral action: An analysis of 18 country case studies. 2008. [acessado 2015 agosto 17]. Disponível em: http://www.who. int/social_determinants/resources/health_equity_ isa_2008_en.pdf.

36. Wagemakers A, Vaandrager L, Koelen MA, Saan H, Leeuwis C. Community health promotion: A framework to facilitate and evaluate supportive social environments for health. Eval Program Plann 2010; 33(4):428-435.

37. Shankardass K, Solar O, Murphy K, Greaves L, O'Campo P. A scoping review of intersectoral action for health equity involving governments. Int J Public Health 2012; 57(1):25-33.

38. Ndumbe-Eyoh S, Moffatt H. Intersectoral action for health equity: A rapid systematic review. BMC Public Health 2013; 13:1.
39. Akerman M, de Sá RF, Moyses S, Rezende R, Rocha D. Intersectoriality? intersectorialities! Cien Saude Colet 2014; 19(11):4291-4300.

40. Moysés ST, Sá RF. Local health promotion plans: Intersetoralities created in the territory. Cien Saude Colet 2014; 19(11):4323-4329.

41. Silva KL, Sena RR, Akerman M, Belga SMM, Rodrigues AT. Intersectoriality, social and environmental determinants and health promotion. Cien Saude Colet 2014; 19(11):4361-4370.

42. Silva R, Dutra R, Soter APM, Gomes MSM, Silva R, Lobato AL. Panel on intersectoriality: Interviews and discussions with managers from six different Brazilian government ministries. Cien Saude Colet 2014; 19(11):4487-4503.

Artigo apresentado em 10/03/2014

Aprovado em 11/02/2015

Versão final apresentada em 13/02/2015 